\title{
Pharmacists' Perceptions of Their Professional Role: Insights into Hospital Pharmacy Culture
}

\author{
Yazid N Al Hamarneh, Meagen Rosenthal, James C McElnay, and Ross T Tsuyuki
}

\begin{abstract}
Background: Numerous studies have demonstrated the positive impacts of pharmacists on patient outcomes. To capitalize on these positive impacts, hospital pharmacy organizations around the world are now calling on pharmacists to shift their focus from distribution of medications to patient outcomes. This new emphasis is consistent with the vision statement for the profession of pharmacy in Canada, as set out in the Blueprint for Pharmacy: "Optimal drug therapy outcomes for Canadians through patient-centred care". Given the ambitious nature of this statement and these goals, it is essential to understand what pharmacists currently think of their practice.
\end{abstract}

Objective: To conduct a qualitative and semiquantitative analysis of hospital pharmacists' perceptions of their role in patient care.

Methods: A researcher posing as a University of Alberta student who was studying how health professionals use language to describe what they do contacted the pharmacy departments of all hospitals in Alberta. The "top-of-mind" approach was used in asking hospital pharmacists 2 questions: (1) How many years have you been practising pharmacy? (2) In 3 or 4 words (or phrases), from your perspective could you please tell me, "What does a pharmacist do"? These techniques were used to minimize the impact of social desirability bias. Content analysis was used to categorize hospital pharmacists' responses into 4 broad categories: patient-centred, drug-focused, drug distribution, and ambiguous.

Results: A total of 103 phone calls were made to hospital pharmacies, and 85 pharmacists contacted in this way were willing to participate in the survey. Hospital pharmacists provided 333 individual responses to the question about their activities. Of these, $79(23.7 \%)$ were patientcentred, 98 (29.4\%) were drug-focused, and $82(24.6 \%)$ were in the drug-distribution category. Ambiguous responses accounted for the remaining $74(22.2 \%)$.

Conclusion: Aspects of care categorized as other than patient-centred should not be construed as unimportant. However, the fact that they were reported in this survey more frequently than patient-centred aspects suggests that hospital pharmacists in Alberta may have not fully embraced the concept of patient-centred care as outlined in the Blueprint for Pharmacy.

Key words: patient-centred, drug-focused, drug distribution, top-ofmind approach, hospital pharmacist, pharmacy culture

\section{Can J Hosp Pharm 2011;64(1):31-35}

\section{RÉSUMÉ}

Contexte : De nombreuses études ont montré les influences positives des pharmaciens sur les résultats thérapeutiques. Pour tirer parti de ces influences positives, les organismes de pharmacie hospitalière à l'échelle planétaire demandent donc aux pharmaciens de passer d'une pratique axée sur la distribution des médicaments à une pratique axée sur les résultats cliniques. Cette démarche est conforme à l'énoncé de vision du Plan directeur pour la pharmacie concernant la profession de pharmacien au Canada: " Procurer aux Canadiens un traitement médicamenteux aux résultats optimaux par des soins axés sur le patient. "Étant donné l'objectif ambitieux sous-tendant cet énoncé et les buts de ce plan, il est impératif de connaître l'opinion qu'ont actuellement les pharmaciens de leur profession.

Objectif: Effectuer une analyse qualitative et semi-quantitative des perceptions qu'ont les pharmaciens d'hôpitaux de leur rôle dans les soins aux patients.

Méthodes : Un chercheur s'est fait passer pour un étudiant de l'Université de l'Alberta qui étudiait comment les professionnels de la santé utilisaient le langage pour décrire leur travail. Le chercheur a communiqué avec les services de pharmacie d'hôpitaux de l'Alberta et a demandé aux pharmaciens de répondre spontanément aux questions suivantes : 1) Depuis combien d'années exercez-vous la pharmacie? 2) De votre point de vue, pourriez-vous me dire en trois ou quatre mots (ou expressions) "Qu’est-ce que fait un pharmacien? ». Ces techniques visaient à réduire tout biais induit dans une réponse par le désir de plaire. L'analyse du contenu a servi à classer les réponses de chaque pharmacien d'hôpital dans les quatre grandes catégories de pratique suivantes : axée sur le patient, axée sur les médicaments, axée sur la distribution des médicaments ou réponse ambiguë.

Résultats : Le chercheur a téléphoné en tout à 103 pharmacies d'hôpital et 85 pharmaciens ainsi joints ont accepté de participer au sondage. Les pharmaciens d'hôpitaux ont fourni 333 réponses individuelles à la question concernant leurs activités. De ces réponses, 79 (23,7\%) étaient classées dans la catégorie de pratique axée sur le patient, 98 (29,4\%) à celle axée sur les médicaments et $82(24,6 \%)$ à celle axée sur la distribution des médicaments. Le reste des réponses, soit 74 (22,2\%), tombaient dans la catégorie ambiguë.

Conclusion : Les aspects des soins classés dans une autre catégorie que ceux axés sur le patient ne doivent pas être interprétés comme étant sans importance. Cependant, le fait qu'ils aient été mentionnés durant ce sondage plus souvent que les aspects des soins axés sur le patient porte à croire que les pharmaciens d'hôpitaux en Alberta pourraient ne pas avoir complètement adhéré au concept des soins axés sur le patient tel qu'il est décrit dans le Plan directeur pour la pharmacie.

Mots clés : pratique axée sur le patient, pratique axée sur les médicaments, distribution des médicaments, analyse des réponses spontanées, pharmacien d'hôpital, culture de la pharmacie

[Traduction par l'éditeur] 


\section{INTRODUCTION}

$\mathrm{T}$ here has been a relatively long tradition of clinical activities being performed by pharmacists working within the hospital setting, ${ }^{1}$ and numerous studies have demonstrated the positive impact of pharmacists on patient outcomes. ${ }^{2-5}$ For example, an evaluation of pharmacists' clinical interventions from 1989 to 1998 demonstrated a decrease in mortality with the provision of 7 pharmacy services, specifically drug use evaluation, in-service education provided by pharmacists, monitoring of adverse drug reactions, management of drug protocols, participation on the cardiopulmonary resuscitation team, participation in medical rounds, and completion of admission drug histories. ${ }^{2}$ Hospital pharmacists have also proven their role in improving the safety and efficacy of drug therapy in various patient populations. ${ }^{3,4}$

To capitalize on these successes, hospital pharmacy organizations around the world are now calling on pharmacists to shift their focus from distribution of medications to patient outcomes. ${ }^{6}$ For example, the Hospital Section of the International Pharmaceutical Federation (FIP) developed the Basel Statements, ${ }^{7}$ and the Canadian Society of Hospital Pharmacists (CSHP) recently developed 6 goals in what it has called Vision $2015,{ }^{8}$ both of which emphasize patients' outcomes. This new emphasis is consistent with the vision statement for the profession of pharmacy in Canada, as set out in the Blueprint for Pharmacy: "Optimal drug therapy outcomes for Canadians through patient-centred care."

Given the ambitious nature of these statements and goals, it is essential to understand what front-line pharmacists currently think of their practice. Such understanding may in turn help in developing an understanding of some assumptions of hospital pharmacy culture. In this context, culture can be understood as a group of individuals carrying out particular activities in a specific environment, using a pattern of shared values, beliefs, and assumptions. ${ }^{10-13}$ Understanding the culture is important because of its powerful influence on human behaviour, ${ }^{13}$ as represented by the popular adage from the business literature, "Culture eats strategy for breakfast". ${ }^{14}$ As such, if there is any hope of attaining the goals outlined in both the CSHP's Vision 2015 and the Blueprint for Pharmacy, a better understanding of hospital pharmacy culture is needed. The aim of the study reported here was to conduct a qualitative and semiquantitative analysis of hospital pharmacists' perception of their role in patient care.

\section{METHODS}

\section{Data Collection}

A brief survey of hospital pharmacists was conducted in Alberta. In calculating the required sample size, it was estimated that $35 \%( \pm 10 \%)$ of respondents would use language consistent with patient-centred care. Using Epi Info software, version
6 (Centers for Disease Control and Prevention, Atlanta, Georgia), Stat Calc for population surveys, it was determined that interviews with 85 pharmacists were needed to render a confidence level of $95 \%$. The target number was increased to 103, to reflect the number of hospitals in Alberta. A list of all hospitals in Alberta was obtained from the Alberta Health Services website (www.albertahealthservices.ca/facilities.asp? pid=facilities). The switchboard operator at each hospital was contacted and asked to transfer the call to the pharmacy. An interview was conducted with the first pharmacist at each location who agreed to participate.

One of the researchers (Y.N.A.), posing as a University of Alberta student studying how various health care professionals use language to describe what they do, made the calls. A "top-of-mind" approach, which "examines what people might tell each other in casual conversation", ${ }^{15}$ was used to engage each respondent's adaptive unconscious, those mental processes that are inaccessible to the conscious mind but that influence judgments, feelings, or behaviours. ${ }^{16}$ The slight deception and the "top-of-mind" approach were used to obtain an accurate description of how pharmacists really see themselves, without the interference of social desirability bias (a form of bias that causes participants to provide the responses that they think the researcher wants to hear). ${ }^{17}$

The researcher asked each participant 2 questions: (1) How many years have you been practising pharmacy? (2) In 3 or 4 words (or phrases), from your perspective could you please tell me, "What does a pharmacist do"? The participants were informed that their answers would be recorded by hand. The study was approved by the Health Research Ethics Board of the University of Alberta.

\section{Analysis}

Two researchers (Y.N.A., M.R.) independently coded the responses using definitions of drug distribution (dispensing) and patient-centred care obtained from the implementation plan of the Blueprint for Pharmacy ${ }^{18}$ (Table 1). Further qualitative content analysis revealed a third theme: drugfocused services, i.e., services that focus primarily on a particular drug, drug-related monitoring, or a pharmaceutical or clinical function that is designed to optimize a given drug therapy (e.g., pharmacokinetic monitoring services; see Table 1). ${ }^{19,20}$ A fourth theme ("ambiguous") was used for responses that did not fit within any of the other themes. More specifically, if the response could have been categorized in multiple categories (patient-centred, drug-focused, and drug distribution), or if the context of the response did not allow categorization, it was considered ambiguous. ${ }^{21}$ After independent coding was complete, the 2 researchers sat together and compared their coding. Differences were resolved by discussion; if agreement could not be reached, differences were resolved by consultation with a third researcher (R.T.T.). 
Table 1. Definition of Themes

\begin{tabular}{ll} 
Theme & \multicolumn{1}{c}{ Definition } \\
\hline Patient-centred & $\begin{array}{l}\text { The merging of several models of health care practice (including patient education, } \\
\text { self-care, and evidence-based care) into } 4 \text { broad areas of intervention: communication } \\
\text { with patients, partnership with patients, health promotion, and delivery of care }{ }^{18}\end{array}$ \\
\hline Drug-focused & $\begin{array}{l}\text { Provision of information about a particular medication OR a particular pharmaceutical } \\
\text { function (e.g., a pharmacokinetic service) that is designed to optimize a given } \\
\text { outcome of drug therapy for the patient OR drug-related monitoring (e.9., adverse } \\
\text { drug events, interactions) and the taking of drug histories }{ }^{19,20}\end{array}$ \\
\hline Drug distribution & $\begin{array}{l}\text { Interpretation and evaluation of a prescription, selection and manipulation or } \\
\text { compounding of a pharmaceutical product, labelling and supply of the product } \\
\text { in an appropriate container according to legal and regulatory requirements, and } \\
\text { provision of information and instructions by a pharmacist, to ensure safe and effective } \\
\text { use of the drug by the patient }{ }^{18}\end{array}$ \\
\hline
\end{tabular}

Table 2. Examples of Responses by Theme

\begin{tabular}{|c|c|}
\hline Theme & Examples* \\
\hline Patient-centred & $\begin{array}{l}\text { "Educate, counsel, and provide information about health, disease state, and well-being" } \\
\text { "Alter the dose or change the medicine if the patient is not improving" } \\
\text { "Work as member of the health care team to improve individual patient's health" } \\
\text { "Patient discharge planning" } \\
\text { "Assessing patient's adherence" }\end{array}$ \\
\hline Drug-focused & $\begin{array}{l}\text { "Calculate the dose" } \\
\text { "Calculating the pharmacokinetics for certain medicines" } \\
\text { "Monitor side effects" } \\
\text { "Monitor drug-drug interaction" } \\
\text { "Provide information about medicines use" }\end{array}$ \\
\hline $\begin{array}{l}\text { Drug distribution } \\
\text { (dispensing) }\end{array}$ & $\begin{array}{l}\text { "Dispense prescriptions" } \\
\text { "Distribute medicines to the wards" } \\
\text { "Prepare and dispense special medicines" } \\
\text { "Order medicines to ensure sufficient stock levels" }\end{array}$ \\
\hline Ambiguoust & $\begin{array}{l}\text { "First contact point with the patient" } \\
\text { "Train pharmacy students" } \\
\text { "Supervise the other staff and look after the pharmacy " } \\
\text { "Organize the workload in the pharmacy" }\end{array}$ \\
\hline
\end{tabular}

Statistical analyses, including analysis of variance and $\chi^{2}$ tests, were performed to assess any differences in responses related to respondents' years in practice or the location of the hospital (urban [population $>10000$ ] versus rural [population $\leq 10000])$.

\section{RESULTS}

Of the 103 telephone calls to hospital pharmacies, 85 led to contact with hospital pharmacists who agreed to participate in the study. In 7 instances, there was no pharmacist on site, at 1 hospital the pharmacist declined participation, and at 10 hospitals, a pharmacy technician, rather than a pharmacist, was on site. Of the 85 pharmacists who participated, 52 were based in rural settings. The average number of years in practice was 20.9 years (standard deviation 10.4 years).

The 85 pharmacists provided a total of 333 responses to the question about their activities (see Table 2 for examples). Patient-centred responses accounted for 79 (23.7\%) of the total responses, drug-focused services accounted for 98 (29.4\%), and $82(24.6 \%)$ responses were in the drug-distribution category. The remaining 74 responses $(22.2 \%)$ were categorized as ambiguous.

An examination of the first activity reported by each hospital pharmacist was also undertaken. More than half of the participants (51 of 85) reported either a drug-focused or a drug-distribution activity first, and 21 provided a patientcentred activity as the first response. Additional statistical analyses showed no significant differences in hospital pharmacists' responses in relation to years in practice or location of the hospital (urban versus rural).

\section{DISCUSSION}

Both the CSHP and the Canadian Pharmacists Association $(\mathrm{CPhA})$ have developed ambitious visions for the future of hospital pharmacy practice in Canada through Vision $2015^{8}$ and the Blueprint for Pharmacy, respectively. However, less 
than one-quarter of participants' responses in the present study described what hospital pharmacists do in patient-centred terms. This result may mean that hospital pharmacists have not yet fully embraced the idea of patient-centred care.

This finding supports those of the Hospital Pharmacy in Canada 2007/2008 Report, ${ }^{19}$ which highlighted that only 25\% of inpatient beds were served with the pharmaceutical care model, the definition of which most closely matches that of patient-centred care used in the present study. The findings in the present study also support those of Stuchbery and others ${ }^{22}$ and Wirth and others, ${ }^{23}$ who conducted direct observational studies of the activities of clinical pharmacists. These authors reported that $31.4 \%$ of the observed clinical pharmacist activities in Australia ${ }^{22}$ and $28 \%$ of those in Malta ${ }^{23}$ were patient-centred. Interestingly, in a similar study conducted by our group, community pharmacists in Alberta also provided a low proportion of patient-centred responses $(29 \%)$. $^{21}$

On the basis of previous evidence and the findings of the present study, it seems that hospital pharmacists view themselves primarily as "guardians of medication". Given the definitions of drug-focused and drug-distribution activities, hospital pharmacists seem to believe that their purposes are to ensure that patients are getting their medications in a safe way, to monitor for side effects, and to provide information about medications to physicians, nurses, and patients. Although each of these duties is important to patient care, none is inherently patient-centred.

If hospital pharmacists are working from the cultural assumption that they are "guardians of medication," they may feel that their sole focus should be on medications. As such, the drug would take precedence over the patient, who becomes a mere receptacle of medications rather than a "walking, talking, confusing, disorganized human being". ${ }^{4}$ It must be noted, however, that hospital pharmacists are probably not making a conscious decision to focus more of their attention on drugs. Rather, the underlying assumption in pharmacy culture that has been inferred from the results of the present study makes the transition in practice (from drug-focused to patientcentred) extremely difficult for them to even conceptualize. ${ }^{11}$ Pharmacy managers may also be responsible for directing pharmacists toward more drug-focused activities.

Unfortunately, this cultural assumption contradicts the visions set out by both the CSHP and the CPhA. As is widely accepted in the business literature, if the culture and the strategic approach to practice change do not align, any change or advancement becomes almost impossible. ${ }^{14}$ Although the cultural assumption that hospital pharmacists are "guardians of medication" is likely one of many under which hospital pharmacists function, it provides some insight into why patient-centred care may not be as prevalent as it could be within hospital settings. As such, further examination and understanding of hospital pharmacy culture is imperative if the visions of the CSHP and the $\mathrm{CPhA}$ are to be attained.
This study had some limitations. Hospital pharmacists were contacted through each hospital's switchboard. A potentially unintended consequence of this approach may be that the pharmacist with whom the researcher spoke was primarily responsible for dispensing medication (most hospital pharmacists have a combination of clinical and dispensing duties on a rotational basis). Another potential limitation relates to the restricted response parameters given to each respondent. Had the pharmacists been given more time to think about their responses, they might have answered differently. However, the intention of the methodological approach used in the present study was to engage the adaptive unconscious and to avoid social desirability bias. We feel that the results are generalizable to at least Alberta, since we called all hospital pharmacies, rather than a sample of them. Although not the focus of this study, it would have been interesting to probe deeper into pharmacists "top-of-mind" responses to gain further insight.

Hospital pharmacists may have not fully embraced patient-centred care as outlined in the Blueprint for Pharmacy. Consequently, the question becomes, "Do hospital pharmacists want to be patient-centred in their practice?" If so, the results of this survey should be taken not as representing defeat, but rather as a call to action. According to Fritz, author of The Path of Least Resistance for Managers, the first step in enacting change in an organization or profession is to precisely define reality. ${ }^{25}$ While the results of this survey begin to describe the culture of hospital pharmacy, more work is needed.

\section{References}

1. Cobaugh DJ, Amin A, Bookwalter T, Williams M, Grunwald PE, Lacivita C, et al. ASHP-SHM joint statement on hospitalist-pharmacist collaboration. Am J Health Syst Pharm 2008;65(3):260-263.

2. Bond CA, Raehl CL. Clinical pharmacy services, pharmacy staffing, and hospital mortality rates. Pharmacotherapy 2007;27(4):481-493.

3. Sanghera N, Chan PY, Khaki ZF, Planner C, Lee KKC, Cranswick NE, et al. Interventions of hospital pharmacists in improving drug therapy in children: a systematic literature review. Drug Saf 2006;29(11):1031-1047.

4. Bosma L, Jansman FG, Franken AM, Hartig JW, Van den Bemt PM. Evaluation of pharmacist clinical interventions in a Dutch hospital setting. Pharm World Sci 2008;30(1):31-38.

5. Makowsky MJ, Schindel TJ, Rosenthal M, Campbell K, Tsuyuki RT, Madill HM. Collaboration between pharmacists, physicians and nurse practitioners: a qualitative investigation of working relationships in the inpatient medical setting. J Interprof Care 2009;23(2):169-184.

6. LeBlanc JM, Dasta JF. Scope of international hospital pharmacy practice. Ann Pharmacother 2005;39(1):183-191.

7. The Basel Statements on the future of hospital pharmacy. Am J Health Syst Pharm 2009;66(5 Suppl 3):S61-S66.

8. Canadian hospital pharmacy 2015 (CSHP 2015). Ottawa (ON): Canadian Society of Hospital Pharmacists; 2007. 9 pp.

9. Blueprint for pharmacy: the vision for pharmacy. Ottawa (ON): Canadian Pharmacists Association; 2008. 12 pp.

10. Holland CK. An ethnographic study of nursing culture as an exploration of determining the existence of a system of ritual. J Adv Nurs 1993; 18(9):1461-1470.

11. Langton N, Robbins SP. Organizational behaviour. 4th ed. Toronto (ON): Prentice Hall; 2007. 
12. Bloor G, Dawson P. Understanding professional culture in organizational context. Organ Stud 1994;15(2):275-295.

13. Kotter JP, Heskett JL. Corporate culture and performance. New York (NY): The Free Press; 1992.

14. Fein IA, Corrato RR. Clinical practice guidelines: culture eats strategy for breakfast, lunch and dinner. Crit Care Med 2008;36(4):1360-1361.

15. Moskowitz HR, Beckley JH, Resurreccion AVA. Sensory and consumer research in food product design and development. Ames (IA): WileyBlackwell; 2006.

16. Harris KS. Strangers to ourselves: discovering the adaptive unconscious by Timothy Wilson [book review]. Hum Nat Rev 2003;3:488-490.

17. Matthews BA, Baker F, Spillers RL. How true is true? Assessing socially desirable response bias. Qual Quant 2003;37(3):327-335.

18. Blueprint for pharmacy implementation plan: achieving the vision. Ottawa (ON): Canadian Pharmacists Association; 2009. 47 pp.

19. Bussières JF. Clinical pharmacy services. In: Babich M, Hall KW, Johnson N, Macgregor P, Roberts N, Bussières JF, et al., editors. Hospital pharmacy in Canada 2007/2008 report. p. 4-24. Eli Lilly; 2009 [cited 2010 Jan 23]. Available from: www.lillyhospitalsurvey.ca/hpc2/content/2008_ report/clinpharmacyserv.pdf

20. Dooley MJ, Allen KM, Doecke CJ, Galbraith KJ, Taylor GR, Bright J, et al. A prospective multicentre study of pharmacist initiated changes to drug therapy and patient management in acute care government funded hospitals. BrJ Clin Pharmacol 2004;57(4):513-521.

21. Rosenthal MM, Breault RR, Austin Z, Tsuyuki RT. Pharmacists' self perception of their professional role: insights into community pharmacy culture [poster]. Canadian Pharmacists Association national conference; 2010 May 15-18; Calgary (AB).

22. Stuchbery P, Kong DCM, DeSantis GM, Lo SK. Identification by observation of clinical pharmacists' activities in a hospital inpatient setting. Pharm Pract 2007;5(1):10-16.
23. Wirth F, Azzopardi LM, Gauci M, Adami MZ, Serracino-Inglott A. Time and motion study for pharmacists' activities in a geriatric hospital. Int J Pharm Pract 2009;17(6):373-376.

24. Taylor JS. Confronting "culture" in medicine's "culture of no culture". Acad Med 2003;78(6):555-559.

25. Fritz F. The path of least resistance for managers: designing organizations to succeed. San Francisco (CA): Berrett-Koehler Publishers, Inc; 1999.

Yazid N Al Hamarneh, BSc, PhD, is a Postdoctoral Research Fellow, Epicore Centre, University of Alberta, Edmonton, Alberta.

Meagen Rosenthal, BA, MA, is the Project Coordinator, Epicore Centre, University of Alberta, Edmonton, Alberta.

James C McElnay, BSC, PhD, FPSNI, FRPharmS, FACCP, is a Professor in Pharmacy Practice, School of Pharmacy, Queen's University, Belfast, Ireland.

Ross T Tsuyuki, PharmD, MSc, FCSHP, is Associate Professor of Medicine, Epicore Centre, University of Alberta, Edmonton, Alberta.

\section{Address correspondence to:}

Dr Ross T Tsuyuki

Epicore Centre

University of Alberta

220 College Plaza

Edmonton AB T6G 2C8

e-mail: ross.tsuyuki@ualberta.ca

\section{Acknowledgments}

We would like to thank all the hospital pharmacists who participated in this study.

\section{CISADL 2010}

\section{Order your copy of the 2010 Canadian Investigational \& Special Access Drug List today!}

\section{Please use the CSHP order form found online to place your order:}

\section{http://www.cshp.ca/productsServices/otherPublications/canadianInvestigational e.asp}

The CISADL is a compilation of drugs that are currently not marketed in Canada and may have Investigational or Special Access status with Health Canada. This list is not endorsed by Health Canada's Special Access Program. For precise information about the regulatory status of a drug, contact the Special Access Program directly. Entries to the list are contributed to by several Drug Information Centres across Canada and by Canadian drug manufacturers. In cases where non-marketed drugs do not appear on the list, foreign references should be consulted. The content of the list includes generic name and strength/concentration, dosage form, pharmacology/therapeutic use, trade and code name, source (manufacturer/distributor), and comments. Available in English only.

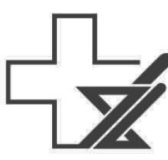
Société canadienne des pharmaciens d'hôpitaux 